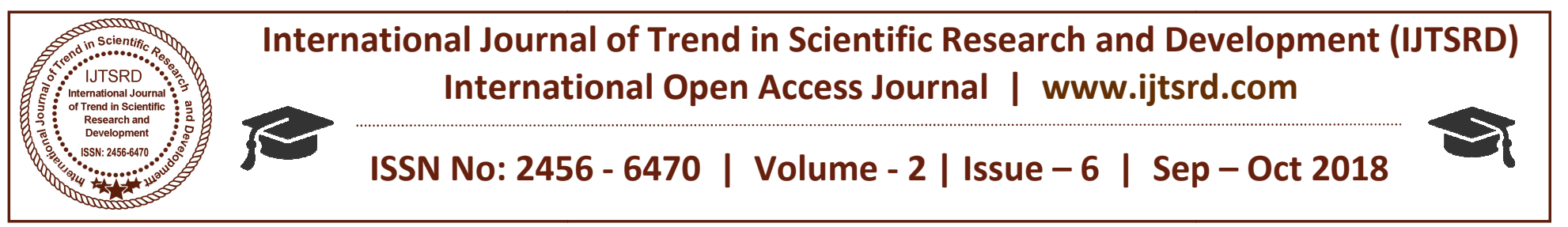

\title{
Matlab/Simulink Model of Sinusoidal PWM For Three-Phase Voltage Source Inverter
}

\author{
Asha Durafe \\ Assistant Professor, Shah and Anchor Kutchhi Engineering College, Maharashtra, India
}

\begin{abstract}
This paper concentrates on modeling and simulation of single phase inverter as a frequency changer modulated by sinusoidal Pulse Width Modulation (PWM) technique. An inverter is a circuit that converts DC sources to AC sources. To judge the quality of voltage produced by a PWM inverter, a detailed harmonic analysis of the voltage waveform is done. Pulse width modulated (PWM) inverters are among the most used power-electronic circuits in practical applications. These inverters are capable of producing ac voltages of variable magnitude as well as variable frequency with less harmonic distortion. The model is executed utilizing MATLAB/Simulink software with the SimPower System Block Set using PC simulation. MATLAB/Simulink is a successful instrument to examine a PWM inverter. Major reasons for using MATLAB are: Faster reaction, accessibility of different simulation devices and the nonappearance of joining issues. In this paper, Insulated Gate Bipolar Transistor (IGBT) is used as switching power device. IGBT is ideal since it high switching speed and also high input impedance. Finally a MATLAB/SIMULINK model for the SPWM is presented. Various simulation results are also included.
\end{abstract}

Keyword: SPWM, Total Harmonic Distortion, MATLAB SIMULINK, Filter Design

\section{INTRODUCTION}

Variable voltage and frequency supply for AC drives is invariably obtained from a three-phase VSI. A number of PWM techniques have been presented to obtain variable voltage and frequency supply [1]. The most popular among those are carrier-based sinusoidal PWM and SVPWM. The major advantages of this scheme are low power consumption, high energy efficient up to $90 \%$ and easy to implement and control. The main focus of this paper is to develop a simple MATLAB/SIMULINK model. The reason for choice of MATLAB/SIMULINK as a development tool is because it is the most important and widely used simulation software and is an integral part of taught programme in most of the universities in Electrical/Electronics Engineering courses. Firstly model of a three-phase inverter in presented on the basis of SPWM representation. This is followed by the basic principle of SPWM. Finally a MATLAB/SIMULINK model for the SPWM is presented.

\section{Coltage Source Inverter:}

The type of inverter where the in dependently controlled ac output is a voltage wave form, the output voltage waveform is mostly remaining unaffected by the load. Due to this property, the VSI have many industrial applications such as adjustable speed drives and also in Power system for Flexible AC Transmission.

\section{A. Single Phase Full wave Bridge Inverter:}

It consists of two arms with a two semiconductor switches on both arms with anti parallel freewheeling diodes for discharging the reverse current. In case of resistive-inductive load, the reverse load current flow through these diodes. These diodes provide an alternate path to inductive current which continue so flow during the Turn OFF condition.

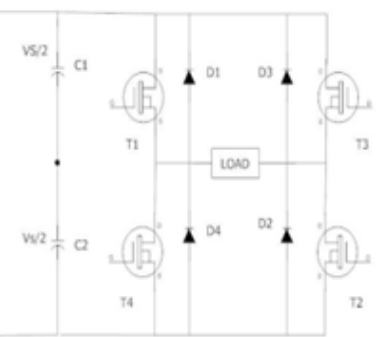

Fig1: Single Phase Full wave Bridge Inverter 


\begin{tabular}{|c|c|c|c|c|c|c|}
\hline II & T2 & T) & TH & $V_{i}$ & $V_{t}$ & $V_{a t}$ \\
\hline$\overline{\alpha N}$ & Off & $0 \mathrm{OFF}$ & $0 N$ & $\frac{\sqrt{n}}{2}$ & $-\frac{1}{2}$ & $T_{s}$ \\
\hline Off & $\alpha 8$ & $0 \mathrm{~N}$ & 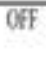 & $+\frac{V}{2}$ & $+\frac{V s}{2}$ & $\sqrt{3}$ \\
\hline ON & OFF & $0 \mathrm{~N}$ & OfF & $\frac{V_{n}}{2}$ & $-\frac{V}{2}$ & 0 \\
\hline OHF & $0 \mathrm{~N}$ & $0 \mathrm{OF}$ & $0 \mathrm{~N}$ & $-\frac{V_{1}}{2}$ & $+\frac{V_{3}}{2}$ & 0 \\
\hline
\end{tabular}

Table 1: Switching States

The switches are T1, T2, T3 and T4. The switches in each branch is operated alternatively so that they are not in same mode (ON /OFF) simultaneously .In practice they are both OFF for short period of time called blanking time, to avoid short circuiting. The switches T1 and T2 or T3 and T4 should operate in a pair to get the output. These bridges legs are switched such that the output voltage is shifted from one to another and hence the change in polarity occurs in voltage waveform. If the shift angle is zero, the output voltage is also zero and maximal when shift angle is $\pi$.

\section{B. SPWM (Sinusoidal Pulse Width Modulation Technique):}

This type of modulation is implemented by comparing a sinusoidal modulating signal $\mathrm{Vm}(\omega \mathrm{t})=\mathrm{Vm}-\sin \omega \mathrm{t}$ with a triangular carrier signal of maximum height $\mathrm{Vc}$ [8]. The natural intersection of $\mathrm{Vm}(\omega \mathrm{t})$ and $\mathrm{Vc}(\omega \mathrm{t})$ determine both the onset and duration of the modulated pulses. PWM gives an approach to diminish the Total Harmonic Distortion (THD) of load current. The THD prerequisite can be met all the more effortlessly when the yield of PWM inverter is separating. The unfiltered PWM yield will have a generally high THD, yet the harmonic will be at the much higher frequencies than for a square wave, making sifting effectively. The aggregate harmonic distortion, or THD, is characterized as the proportion of the total of the powers of every single harmonic segment to the power of the central. Control of the switches for the sinusoidal PWM yield requires a reference flag (tweaking or control flag) which is a sinusoidal wave and a bearer flag which a triangular wave that control the exchanging frequency. There two kind of the exchanging for PWM, unipolar exchanging and bipolar exchanging. In a unipolar exchanging plan for PWM, the yield is changed from either high.
Sinusoidal pulse width modulation technique is adopted in order to reduce the harmonic content of output voltage and to obtain an electrical near sinusoidal output voltage.

\section{Harmonics:}

Harmonics are brought on by non-straight loads that are loads that draw a non-sinusoidal current from a sinusoidal voltage source. Some cases of harmonic creating loads are

$>$ Electric circular segment heaters

$>$ Static VAR compensators

$>$ Inverters

$>$ DC converters

Switch Mode Power Supplies and AC or DC engine drives

This paper describes the Harmonic examination of Single Phase inverter with Pulse Width Modulation (PWM). The Simulink demonstrate for both straightforward and down to earth inverter has been designed in MATLAB.

\section{Simulation Results:}

Simulation model have been designed and implemented using MATLAB SIMULINK tool. The proposed Simulink model has been shown in figure 2 and figure 3 in which modeling and simulation of single phase inverter as a frequency changer modulated by Pulse Width Modulation (PWM) has been designed. Load voltage, load current have been shown in figure 4 . The PWM generation is shown in figure 5 and the Harmonic profile with THD value is shown in figure 6 . The different parameters of the inverter, for example, R, C and Filter plane are shifted and the subsequent voltage and current diagrams has been examined.

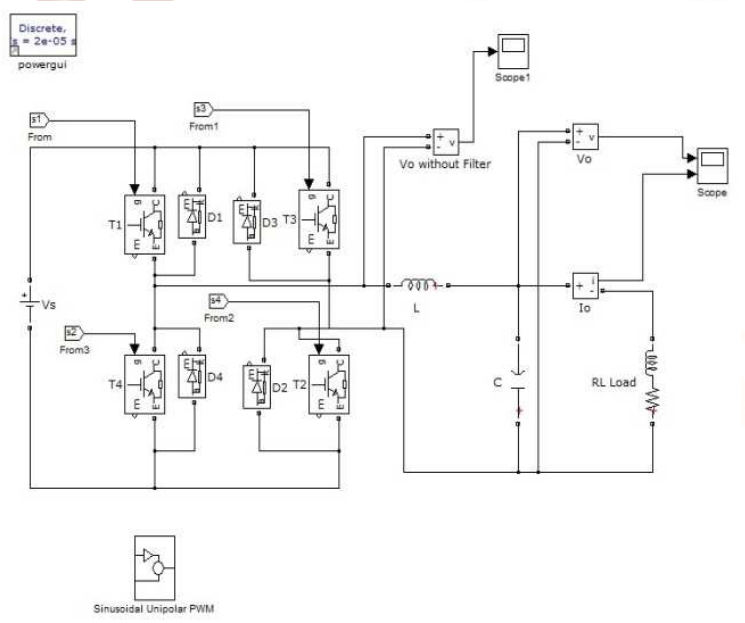

Figure 2: Single phase SPWM Inverter 
International Journal of Trend in Scientific Research and Development (IJTSRD) ISSN: 2456-6470

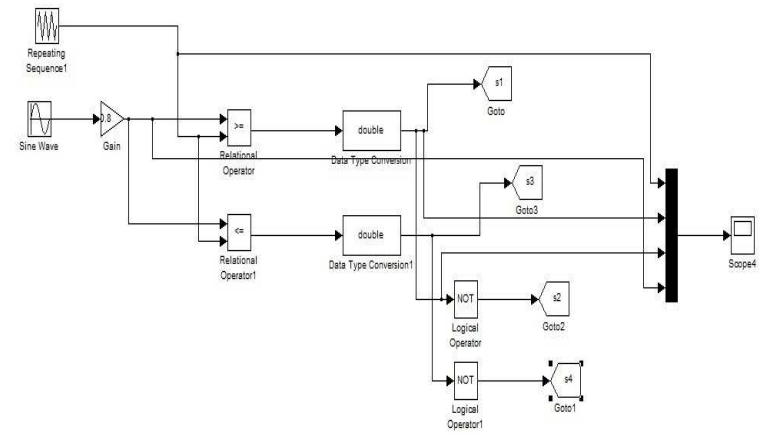

Figure 3: SPWM Generator

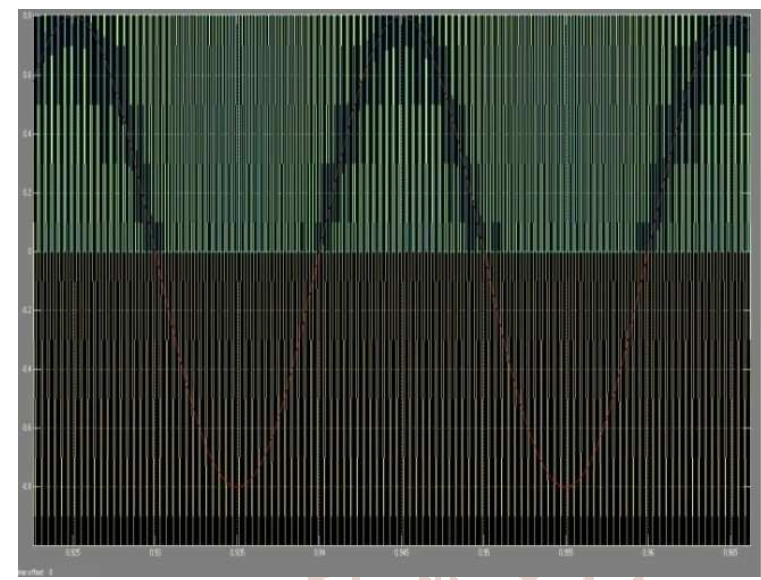

Figure 4: SPWM Waveform

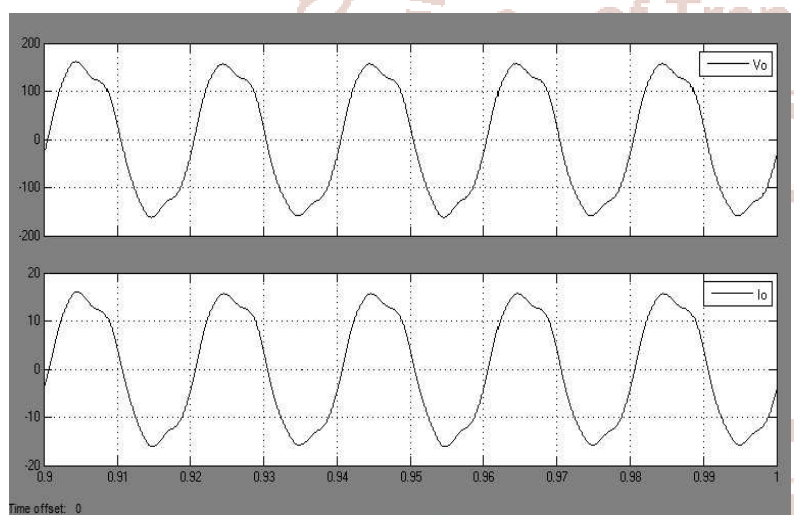

Figure 5: Load voltage and load current

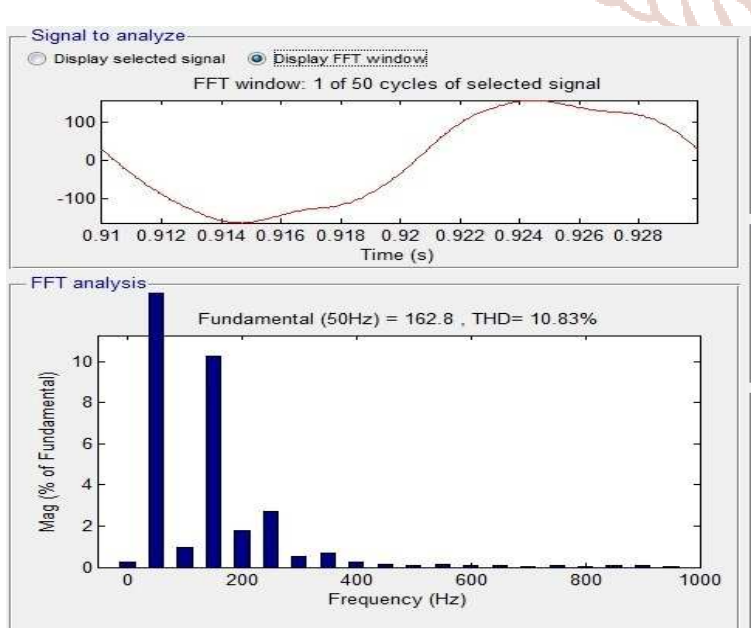

Figure 6: THD of Output Voltage Waveform for

Single Pulse Width Modulated Inverter

\section{Conclusion:}

This paper describes the Harmonic analysis of Single Phase inverter with Pulse Width Modulation (PWM). It includes both practical inverter circuit and PWM generator circuit. The Simulink models for both the circuits have been simulated in MATLAB/SIMULINK. Its various parameters such as R, L load and filter design components are varied and the resulting voltage and current graphs have been studied.

\section{References:}

1. Kim. J, Choi. J \& Hong. H, "Output LC Filter Design of Voltage Source Inverter Considering the Performance of Controller" IEEE Conference Publications, 2000.

2. Lin. W. Song \& Huang. I. Bau "Harmonic Reduction in Inverters by Use of Sinusoidal Pulse Width Modulation" IEEE Transactions on Industrial Electronics - IEEE TRANS IND ELECTRON, vol. IECI-27, no. 3, pp. 201-207, 1980

3. Gole. A. M "Harmonic Elimination in SPWM Inverter"1994, Halifax, Canada.

4. Ming Li, Dong Dai \& Xikui Ma, "Slow-Scale and Fast-Scale Instabilities in Voltage- Mode Controlled Full-Bridge Inverter" Journal: Circuits Systems and Signal Processing - CIRC SYST SIGNAL PROCESS, vol. 27, no. 6, pp. 811-831, 2008.

5. Maswood. Ali. I \& Al-Ammar. Essam "Analysis of a PWM Voltage Source Inverter with PI Controller under Non-ideal conditions" International Power Engineering ConferenceIPEC, 2010.

6. Anand. D \& Jeevananthan .S "Modeling and Analysis of Conducted EMI Emissions of a Single-Phase PWM Inverters" Asian Power Electronics Journal, Vol. 4, No.3 December 2010.

7. Crowley. Ian. F \& Leung. H. F "PWM Techniques: A Pure Sine Wave Inverter" Worcester Polytechnic Institute Major Qualifying Project, 2010.

8. J.M.D. Murphy and F.G. Turnbull, Power Electronic Control of AC motors, Pergamon Press, 1988.

9. M. H. Rashid, Power Electronics, Prentice-Hall, 1998.

10. Ned Mohan, M.Undeland and P.Robbins, Power Electronics, John Wiley \& Sons, 1995. 